\title{
THE USE OF FORUM THEATRE AS CREATIVE PEDAGOGY IN TEACHING AND LEARNING OF MORAL EDUCATION IN SECONDARY SCHOOLS IN MALAYSIA
}

\author{
Nadarajan Thambu ${ }^{1}$, PhD \\ Associate Professor, \\ Sultan Idris Education University \\ Malaysia
}

\author{
Ganesan Shanmugavelu ${ }^{2}, \mathbf{P h D}$ \\ Senior Lecturer, \\ Institute of Teacher Education Ipoh Campus, \\ Malaysia
}

\author{
Zulkufli Mahayudin ${ }^{3}$ \\ Senior Lecturer, \\ Institute of Teacher Education Ipoh Campus, \\ Malaysia
}

Article DOI: https://doi.org/10.36713/epra4961

\begin{abstract}
Implementing teaching and learning, to raise the dimension of moral reasoning among students, is still a major challenge to secondary school teachers. Pedagogy and classroom teaching strategies is important to stimulate students to think critically and pro-active in addressing a moral and social conflict. Furthermore, one of the aspirations of Malaysian Education Blueprint 2013-2025 is to produce a creative, innovative and critical thinking society in Malaysia. Conventional classroom teaching seems difficult to attract secondary school students to engage physically and mentally in moral learning process. In this regard, the use of pedagogical strategies and innovative teaching techniques can stimulate students' cognitive skills to current demands. Therefore, this article discusses the use of Forum Theatre as a creative pedagogical strategies in teaching and learning of moral education in secondary school. Creative teaching strategies that are able to develop reasonable thought and justification, is essential for the development of human capital in the era of globalization.
\end{abstract}

KEYWORDS : Pedagogy, Creativity, Moral Education, Technique, Strategies, Teaching, Learning

\section{INTRODUCTION}

Moral Education (ME) is a core subject in primary and secondary education system in Malaysia. This subject is compulsory for all non-Muslim students in government and private schools (standard 1 to form 5).This subject focuses on the effort to instill spiritual and moral strength through experiential and daily virtues of Malaysian society that are found in religion, traditions, and cultural rites. A moral person, as defined in the (ME) program is one who abides by the Rukun Negara (National Ideology), is virtuous, responsible, and able to contribute towards the harmony and stability of the country and global community
(Malaysia Ministry of Education, Moral Education Syllabus for Secondary School, 2000, p.v).

One of the objectives of Malaysian Education Blueprint 2013-2025 is to produce Malaysian citizens who appreciate the moral values. In this regard, the process of teaching and learning that occurs in the classroom, as catalyst to produce a holistic generation in terms of intellectual, spiritual, emotional and physical development (Ministry of Education Malaysia, Moral Education Syllabus for Secondary School, 2000). Research by Narvaez and Lapsley (2008) and Thambu, Naidu and Othman (2018) states that there is 
an intimate relationship between teaching practices and student character development.

The curriculum for Moral Education in Malaysia emphasizes the holistic view of students' development. Malaysian National Education Philosophy (FPK), illustrated that:

Education in Malaysia is an effort towards developing the individual's potential as a whole to foster individuals who are balanced and harmonious, intellectually, spiritually, emotionally and physically, based in belief and obeying God. This is a continuous effort to produce Malaysian citizen who are knowledgeable, dynamic, virtuous,

responsible and capable of achieving self-fulfillment as well as providing their service towards the harmony and peace of the family, community and country.

(Vishalache \& Claiborne, pp.226).

In fulfilling these national educational aims, Moral Education should be concerned with educating pupils to understand, know and have the dispositions to act on values, and have the capacity to function as moral agents in the moral sphere (Chang, 2007). Morality or moral behavior is an attitude of mind occurring within a framework of beliefs and commitments. A person's duty to God, country, family or social group is the essential elements in moral behavior (Thambu \& Shanmugavelu, 2016).

Teachers need to perform teaching duties effectively in a classroom environment that is arguably complex and fluid (Cohen \& Geier, 2010). Classrooms are said to have complex environments due to factors such as students, teachers and physical conditions affecting the student's learning process. The classroom environment is fluid because all the events happening inside or outside of the classroom will have an impact on the students. In this situation the teacher must play a role in implementing good teaching techniques designed to maintain student interest. Students should be given enough skills training and moral experience in the classroom, so they can learn the value and internalize it as their self habits (Vishalache, 2011). According to Lickona (1996),

"to develop good character they need many and varied opportunities to apply values such as responsibility and fairness in everyday interactions and discussions,..through repeated moral experiences, students can also develop and practice the moral skills and behavioural habits that make up the action side of character" (pp.96-97).

\section{PROBLEM STATEMENT}

Appropriate teaching techniques are important in the classroom because satisfaction and enjoyment in teaching depend on leading students to cooperate.
Besides providing a safe and comfortable learning environment, teaching techniques can also build self esteem and motivation (Hess, 2009). The role of teachers as transmitters of values and moral content and students as passive receptors has been a teaching pedagogy of Moral Education in Malaysia. One way method of teaching and exam oriented pedagogy (Liau et al., 2003) makes the subject boring for students. Students are not interested in attending the Moral Education class. Lack of interest in this subject contributes to the unwanted behavior among school children (Ibrahim Bajunid, 2012). There is a gap between the moral syllabus and how the students approach moral conflict in their daily lives (Vishalache, 2011).

In this context, the ability to communicate is an essential component for successful teaching. Research by Robinson and Lai (2006) showed a normal means of communication,cannot attract the student attention to focus on learning in the classroom. Conventional technique of teaching is unable to inspire them to get involved in the process of teaching and learning in the classroom. Teaching is essentially a performance (Alam Sher Malik, 2012). A performer needs to be familiar with different ways of presenting ideas and have the skill to implement them creatively. Creativity in teaching is a capacity for producing imaginative, original products or ways of solving problems (Torrance, 1983). In order to enhance this intuitive ability, teachers should explore artistic approaches, that is, approaches which focus on the facial expressions, vocal characteristic, gestures and body movements. Artistic fields of study in education such as theatre normally produce the desired response from students (Nadarajan Thambu, \& Muhammad Hasbi Abdul Rahman, 2017).

Meanwhile, with globalization, Malaysian youth are faced with increasing challenges in resolving social problems. One way of working creatively to enhance learning in the Moral Education classroom is through a technique called Forum Theatre. Forum Theatre techniques have features such as active learning and providing direct experience to students and it is a student-centered learning approach (Osburn, 2010). Artistic approaches to teaching such as Forum Theatre help students become more intuitive and adaptive in their learning (McClimens \& Scott, 2007). In this study, Forum Theatre has been used as creative teaching and learning technique that requires students to participate actively in the process of developing a script, memorizing, engaging in forums, acting and expressing ideas. It allows students to appreciate values and think about what they are doing. 


\section{WHY FORUM THEATRE?}

Forum Theatre techniques are capable of delivering directly a series of training and moral experience in the classroom. If we go by the active learning principle, which Figure 1.1 proves that students tend to remember $90 \%$ of what is done and see if they are doing the real thing. In this approach, students was appreciated as a human being who have full awareness and consciousness to evolve in terms of thoughts, feelings and actions (Gourd \& Gourd, 2011). The purpose of teaching in Forum Theatre is not to guide students to memorise facts and moral content mechanically but to make them involve in the process of inquiry, dialogue, the reality of real life, knowledge, creativity, consciousness and transformation in behaviour (Kincheloe, 2008).

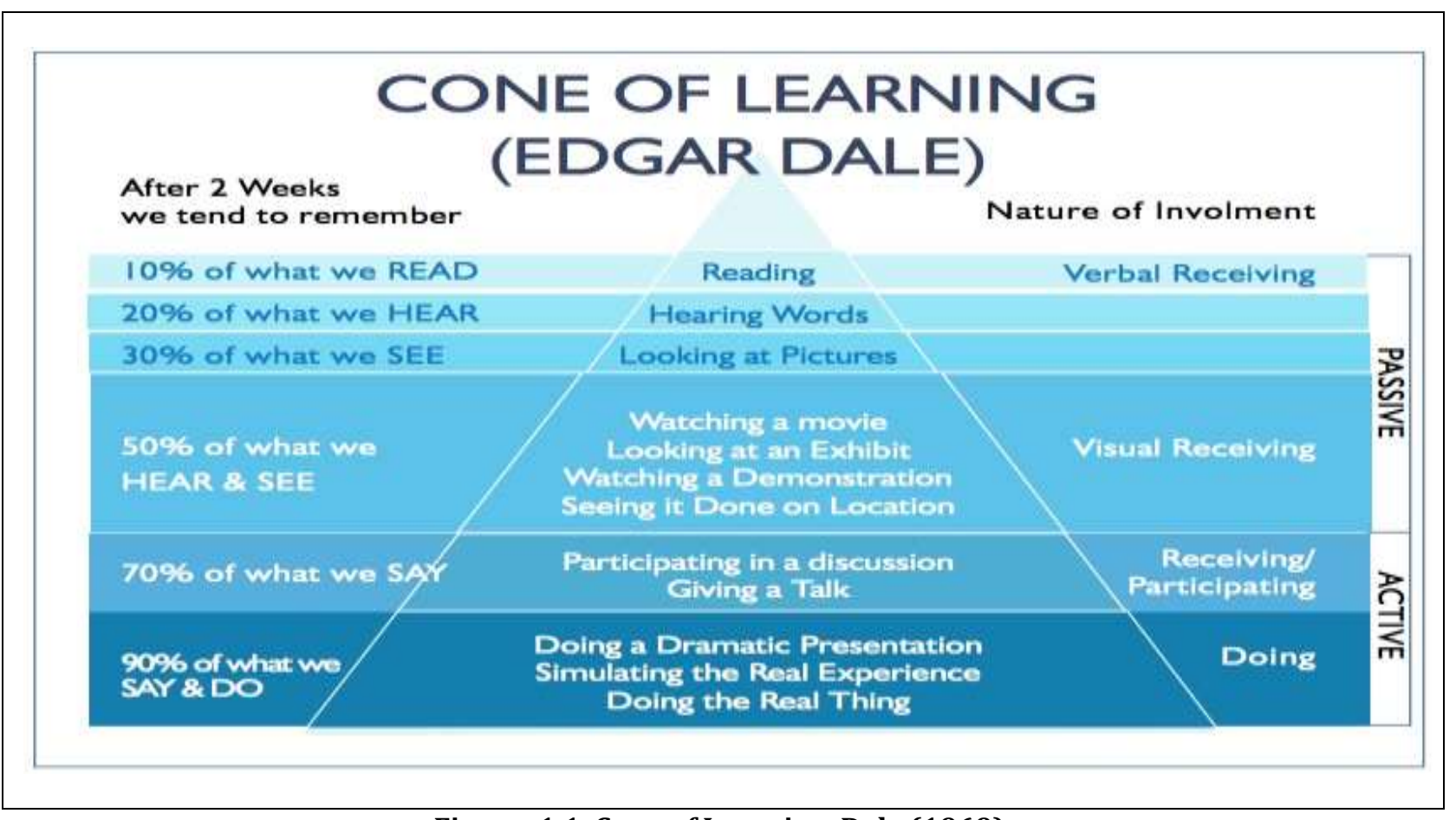

Figure: 1.1. Cone of Learning. Dale (1969).

Pedagogy is a science and art of teaching. How we teach must reflect how our students learn. It must also reflect the world our students will move into. This is a world which is rapidly changing, connected, adapting and evolving. Our style and approach to teaching must emphasize the learning in the 21st century. Even if we have a 21 st Century classroom (flexible and adaptable), a 21 st Century teacher (an adaptor, a communicator, a leader and a learner, a visionary and a model, a collaborator and risk taker) and our curriculum reflects the new paradigm and we have the facilities and resources that could enable 21st century learning; We will only be a 21 st century teacher if we teach changes as well (Spring, 2006). Our pedagogy must also change. The key features of 21 st Century Pedagogy are:

- Making use of project based learning

- Using problem solving as a teaching tool

- Using 21st C assessments with timely, appropriate and detailed feedback and reflection

- It is collaborative in nature and uses enabling and empowering technologies

- It fosters Contextual learning bridging the disciplines and curriculum areas

- Building technological, information and media fluencies

- Developing thinking skills (Refer Figure 1.2) 


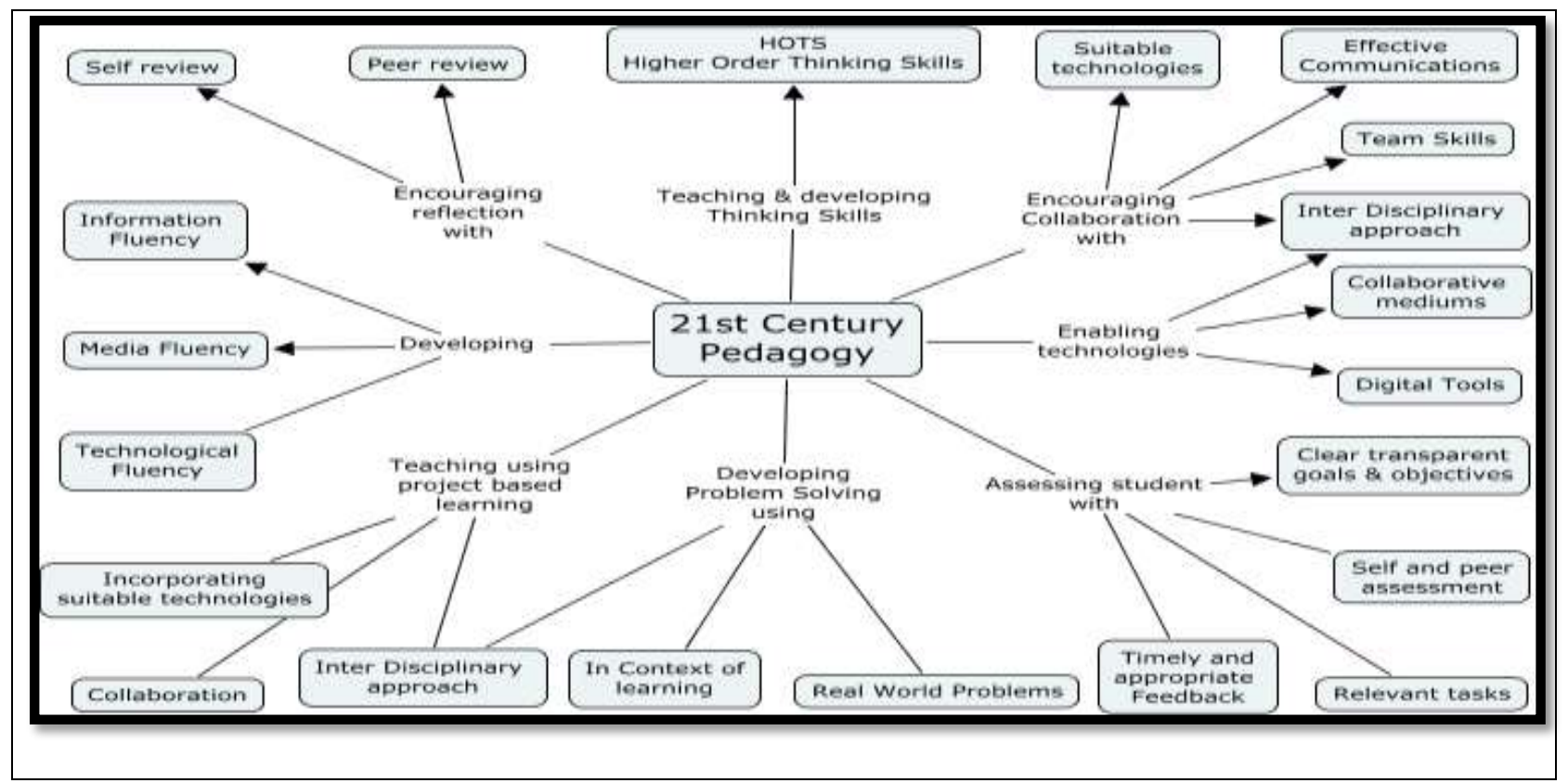

Figure 1.2: 21st Century Pedagogy. (http://www.teachthought.com).

Meanwhile, Forum Theater also meets the characteristics of 21 st century pedagogy (Figure 1.2). Elements in Forum Theater such as 'develop a script' able to develop thinking skills and contextual knowledge. This steps also develop problem solving skills among students, because they use a real-world problems. While the 'anti-model play' also encourage students to work as a team, and collaborate each other. The 'forum' sessions also encourage reflection aspects such as self review and peer review. Besides that, an 'intervention play' also able to develop information fluency, and team skills. Last but not least, the use of Forum Theater in teaching moral education will merge the moral discipline and theater discipline. It has realized the concept of inter-disciplinary approach in 21 st century pedagogy.

\section{METHODOLOGY}

\subsection{Research Design}

This study was conducted using qualitative sampling (Creswell, 2012). A purposive approach to sampling was undertaken (Richards \& Morse, 2007). Form Four science students (18 male and female students of Indian and Chinese ethnicity) from three schools were selected for data collection purposes.

\subsection{Data Collection}

As a form of data triangulation, this study used multiple ways of obtaining qualitative data (Bogdan \& Biklen, 2007). The main method was focus group interviews, in which the selected group of students were interviewed. All interview sessions were recorded, transcribed and data were coded for analysis purposes. All transcribed verbatim reports were returned to the interviewees for them to check the accuracy of what they had said. Apart from that, students' journals were used for analysis from the students' perspectives about the teaching technique and their involvement in Forum Theatre. Other sources of data such as classroom observation to investigate teachers' performance were also used.

\subsection{Instrument}

Instruments such as classroom observation protocol, interview protocol and journal writing method were used to collect relevant data. The content validity of the instruments was assured through comments and criticism from experts in Moral Education and Theatre Education.

\subsubsection{Focus Group Interviews}

Focus group interview protocol, as proposed by Creswell (2012), was used in this study to help the researchers explore, and record the data and information widely about the Forum Theatre usage in developing moral behavior. Information about the ability of Forum Theatre to develop moral practice was also collected. Focus group interviews provide an opportunity for researchers to meet face to face with their study participants, to verify the information collected through observation, and journal entries. The Interview protocol was used by the researchers to focus more on asking questions that could answer the research questions. Interviews also allow researchers to collect opinions, thoughts, insights and experiences of 
the study participants in the study area. In addition, the interview provided an opportunity for researchers to understand what had happened and to access thoughts by study participants about moral practice.

\subsubsection{Observations}

Observation is a process of collecting information openly to get a true picture of the phenomena that occurs at the site of the study (Merriam 2009). Observation is the best way to collect data, about participants' behavior and is capable of collecting non-verbal data (thoughts or ideas) of participants (Creswell, 2012). Observation methods also allow researchers to move away from the perception-based data to data collected directly at the site (Lim, 2007). In this study, researchers used a classroom observation protocol by Seale (1999). Observations to use Forum Theatre through teaching segments that focus on the potential of this technique in developing aspects of moral practices or moral behavior have been implemented.

\subsubsection{Journal Writing}

Two forms of journal, researcher's reflective journal and student's journal, were used to obtain data. A researcher's reflection journal (Bogdan \& Biklen, 2007) was used as a written record of the observations and to express feelings, practice, experience and atmosphere experienced by the researchers in the Forum Theatre technique. The student journal (Piantanida \& Garman, 1999) was used to collect data about how their participation in Forum Theatre influenced their attitude and behavior. Journal supply data in the form of language and words (ideas recorder journal), became a rich source of information, for qualitative approach, and available for analysis without requiring any transcription (Marohaini, 2001). Participants were also asked to record the date, events, locations and teaching sessions every time they wrote a journal entry to facilitate cross-referencing for the researcher during data analysis.

\subsection{Data Analysis}

The thematic approach introduced by Braun and Clarke (2006) was used for data analysis. With the thematic approach, the coding scheme was initially guided by the research questions which provided the main themes and key coding. However, the possibilities of other emerging themes that might emerge from the data were also accepted. Data from various sources and transcription codify into concepts, sub-themes and themes. Data were compiled according to the order based on the breakdown of data into simple categories. Coding in qualitative research such as open coding, axial coding and selective coding is the process of identifying correlates of data into an idea, theme or category (Boeije, 2010). The inductive-deductive cycle of thinking constantly happened in our data analysis process in order to derive at the most valid codes and concepts to answer the research questions. Findings were categorized according to several themes.

\section{FORUM THEATRE}

Forum Theatre is formed from two words namely 'Forum' and 'Theatre'. Forum is derived from the Greek term, meaning an open discussion field. Theatre means a genre of art or a form of communication. The goal of the Forum Theatre is to give the opportunity to the actors and the audience, to express publicly and receive views on the issues presented. This interactive theatre developed by Augusto Boal of Brazil (2008). In the Forum Theatre, the actors will dramatize social problems, or "oppression" that occurs in the community, for the community's views (Babbage, 2004). Forum Theatre will end with an unresolved problem. Then, the audience (spectators) are given the opportunity to stage to explore solutions to the above problems through play. Forum Theatre is widely used in schools to address the issue of racism, sexual prejudice, violence, and bullying (Day, 2002).

Forum Theatre is a creative type of role play developed by a Brazilian dramatist, Boal (Rae, 2013). Forum Theatre is a form of theatre where audiences have the power to suggest and make changes to events on stage. Members of the audience are encouraged to join the action on stage, and to become co-constructors and co-actors. Viewers are given the opportunity to intervene directly in the action and to try to bring the play to a different conclusion. The role of the audience (spectators) is transformed into "spect-actors" in the Forum Theatre. Boal (2006), designated the audienceactor as "spect-actors". He further argues that the theatre is the art of looking at ourselves because all men are actors.

According to Augusto Boal (2006), Forum Theatre is not in accordance with the classical notion of theatre, a form of performance "spectacle" alone. Forum Theatre involve "dialogue" with the audience and not a "one-way conversation", as is the case in conventional theatre, where intransitive relationships take over. In conventional theatre, everything moved from the stage to the auditorium. Emotions, ideas, and issues of morality and moved in that direction, none of which move toward opposite (Boal, 2006). Instead, the Forum Theatre actors not only delivere their speech, but the audience also have to answer what is seen and heard. Actually, Forum Theatre is a creation of a discussion forum or space to analyze, discuss, and explore group solutions against injustice (Boal, 2008). 
In Forum Theatre, gap between actors and audience have been eliminated. Audience (spectators) will change roles to become an actor (spect-actors). Spect-actors are given the opportunity to change the scene presented by assuming the role of a character is acting to bring about a change in the outcome of the story. Spect-actors will make a difference in the outcome of the story through improvisation with the ideas of other members of society. The goal of Forum Theatre is explore clearer understanding of a social conflict that exists. In addition, the Forum Theatre also supports the goal of empowering community members to intervene in order to change the social conflicts plaguing their society (Boal, 2006).

Forum Theatre became a social therapy, in which the audience is not just watching the play, but even participated in the staging. Viewers can comment on the action, to intervene directly, participate as a character in the show, and try to bring the play to a different conclusion. As it turns out, the audience is no longer passive recipients. They are active audience (spect-actor) who bring their own experience and suggestions to the problems presented in the theatre. According to Augusto Boal (2008), one of the Forum Theatre motives is each person is responsible for their own actions and, when there is a problem, everyone should be involved in finding ways to solve problems.

\section{FORUM THEATRE AS TEACHING TECHNIQUE}

Students were involved in four steps of Forum Theatre as recommended by Boal (2008). These four steps are (a) develop a script (b) anti-model play (c) forum, and (d) intervention play. The following is a discussion of how the student used them and how it worked out in the Moral Education classroom to develop students cognitive, affective and psychomotor aspect.

\subsection{Develop a Script}

In this step, students are asked to develop a script based on their own experiences of daily life. The objective of this task is to train participants to develop a script based on their own experience. In this study, the participants collaborated in developing a script about their shared challenges. In this context the focus was "moral conflict" and the scenario could be almost any topic which resonated with "oppression". Participants wrote three scripts to demonstrate the problems causing the oppressive situation. Script A related to conflicts between road users and police officers, script B involved a conflict between students and teachers in the school premises and script $\mathrm{C}$ was about conflict between children and parents in the family.

\subsection{Anti-Model Play}

After composing the script, students had to act out the script developed earlier. The developed script was acted out by the students for class viewing. Their moral conflict scene was performed as an anti-model play. Although Boal (2008), gave the terms of an 'antimodel' play, we followed a different one as it was not a model we could relate to and therefore we changed it. It is compulsory for the scene (anti-model play) performed to display oppression or pressure situations, where a character being victimized fails to overcome the persecution. Thus, the issues were clarified and the students appeared to empathize with what they experienced. The original performance always ends in an unsolved form, with an undesirable challenge for the victimized character.

\subsection{The Forum}

After the anti-model play is completed, another step is immediately conducted by the "Joker". In Forum Theatre, the facilitator of the action is the Joker. The Joker takes responsibility for the logistics of the process and functions as a neutral link between the actors and the audience. The Joker discusses with the audience the problems that appear in the presentation and possible solutions are proposed to overcome the above problems. The Joker then asks the audience to figure out the right solution or idea that can be implemented to resolve the conflict experienced by the oppressed characters in the play. Discussion, improvisation and audience participation is known as "forum", in Forum Theatre. In our case, the appropriate solutions were discussed in a forum session by the participants.

\subsection{Intervention Play}

During intervention steps, the anti-model play was presented for a second time. This time the audience members have the opportunity to intervene and bring the play to a different and improved end. An audience member took the place of an actor to demonstrate his or her ideas for resolving a problem. They can do so by taking on the role of a specified victimized character from the anti-model play. When an audience member feels he or she could play the role of this character more effectively, then they shout "stop", at which point the scene of the play freezes and this audience member takes on the role, trying out alternative and desirable behavior. After that, the Joker will make sure that, the solutions are explored adequately by the audience members and that they are to some extent possible in real life. Boal (2006) wanted the audience to be active members of society, to cooperate in tackling existing conflicts in society. 


\section{FINDINGS AND DISCUSSION}

\subsection{Conducive Environment for Learning}

Forum Theatre was able to create a highly interactive learning environment. It succeeded in creating a classroom environment that supports student learning. Students involved in four steps of Forum Theatre showed a high degree of group trust and willingness to take risks. They are engaged in learning in the classroom physically and mentally through Forum Theatre. Outcomes following interview data indicate that student participation in the conducive classroom environment.

Participant 2: In Moral we can see that we can use Forum Theatre techniques. We already see the fun antics of our friends acting ... it caught our attention. This balance varies with the normal way of teaching. In a typical drama viewer cannot give the idea in Forum Theatre we can give ideas ... and act out ideas through forums and intervention

sessions. This collaboration created group cooperation. [SMKSuria/inter/5.2.18] (Author's translation).

The following is a journal entry of participants:

"All members of the group are very cooperative when it comes to training, some brought the play's prop, some are willing to buy props like a police hat and if problems arise we together solve the problem. All team members have the attitude and determination to write the script and acting in unity" [SMKSinar/Jour/27.2.18] (Author's translation). Classroom observation shows participants are also having fun. They focus and concentrate while performing activities such as discussion (forums) for developing a script, writing a script, participating in an anti-model play and intervention play.

In the meantime, some of the participants commented that the Forum Theatre:

Participant 3: "It's ... it ... stimulate students enjoy ... easy ... but we must have a lot of guts ... and creative .... Teacher must give a lot of time for us to be ready ... then... ok ... if all of us work together then easy for us to create a play. Acting is interesting... and we quickly understand what is shown. We'll really see and hear, the anti-model play takes place in front of our eyes the acting is

lively so we can understand better"[SMKCahaya/inter/22.2.18] (translated version).

In the journal entry, participants noted that:

"It is fun. We are not stress ... no tension now .... if not before ..... many say Moral is boring subjects ... as we always write notes .. notes.. and memorize the values .... if students do not memorize the moral standing to class exhausted ... for shame ... that's why many of us skip Moral Education class. Now when there are activities such as anti- model play, intervention and theater

games, it's more fun, reduce stress" [SMKSinar/jour/7.3.18] (Author's translation).

\subsection{Facilitates Experiential Learning}

Forum Theatre is also able to facilitate experience based or active learning. This finding is consistent with previous studies that indicate the effectiveness and value of involving students in their learning experience through experience and simulation (Boggs, Mickel, \& Holtom, 2007). Chickering and Gamson (1987) described experiential learning as a best practice for students. They emphasized the process which makes learning is meaningful. According to Chickering and Gamson (1987), "learning is not a spectator sport...(students) must talk about what they are learning, write about it, relate it to past experiences, and apply it to their daily lives'(p. iii). Our key teachings in moral education required attitude shifts of our students. Direct experience and first hand exploration which students gain from Forum Theatre activity seemed to be the best way to get there.

Participants declare in a journal entry that:

"We get experience in acting ... and the experience of being in a situation that we are playing ....and this facilitates quickly makes us recalls all the values that we played

We have the experience to find the values that correspond to the situation.... and try out in the intervention play.... We belief we can use the same method to solve problems in real life" [SMKSinar/jour/7.3.18] (Author's translation).

Classroom observation shows that among the key aspects identified through experiential learning is an aspect of creativity and leadership among students. Students are very creative in writing stories together. They are able to write creatively daily experiences encountered by them in the form of an interesting acting script. In one scenario (script B), for example, students are able to show the conflict faced by students and teachers in the school premises well. Conflicts such as one involving a sports teacher who is unaware of student problems, attitudes that do not comply with the classroom rules, the teacher's negligence while on duty and the problems in friendship can be described by the anti-model play for the students [SMKSinar/obser/26.2.18].

Participants were also creative in describing the atmosphere of tension existing between the students and teachers at the school field and in the counseling room well. Researchers felt that the class was energized 
by the experience and the creative product were "owned" by all the participants.

Participant5: "Forum Theatre makes us think ... think out of the box ....and be creative. Students show creativity as we write scripts, write dialogue ... we also have to have the imagination to pretend to be the teacher counselor, teacher ... Man ... and other characters. .... And ... We also need to be creative while acting in intervention play to find an idea, create a role-playing situation, to resolve existing problems and to draw the attention of the audience translation). "[SMKCahaya/inter/12.4.18] (Author's

\subsection{Forum Theatre Stimulates Co-Learning}

Forum Theatre activity stimulates co-learning among participants. Students greatly enjoyed the activities and researchers noted a very high level of participation from all the students in the classroom. The process of acting in an anti-model play or an intervention play prompted laughter and some competition among students. This element of Forum Theatre stimulated participation from all class members. Group members helped each other to solve the problem addressed by the other group through antimodel play. Each group of students generated rich and significant content about their own experiences to create a solution for the problem through intervention play. A deeper understanding of course material was achieved, along with a wealth of connections such as students to material and students to each other [SMKCahaya/obser/8.3.18].

This is evidenced by the following interview:

Participant 5: "If you use Forum Theatre in the Moral Education subject is good.. more

nice, because there is no stress. It will create a 'critical thinking' ... students can cooperate .... and the relationship between teacher and pupil better .... because there is cooperation.... and studying is fun" [SMKCahaya/inter/12.4.18].

Researcher: How Forum Theatre create critical thinking?

Participant 6: "When we compose the script .. we compose it creatively..... while acting in antimodel play..we ... also include a ' sense of humor' ... think of how we can get students' attention ... well ... how to act..." [SMKSinar/inter/24.1.18] (Author's translation).

This conclusion is supported by the following excerpts: Participant 1: "Every group member give in the ideas... All of us discuss together before create the script...the script is our own selfauthored script ... We prepare the props ourselves ".
Participant2: “Acting.... even our own ... we train on our own after school hours ... 20 minutes every day... usually we use school hall for training every day ... Sometimes we like to watch a YouTube to find a way to act" [SMKSuria/inter/9.4.18] (Author's translation). Participant journal entries show that Forum Theatre helps them speak in a more bold and confident way: "Yes, ..confident.. use expressions like ..... well .. let say if we attend our scholarship interview..we have to speak with confidence and courage ... we need to use good expression...acting" [SMKSuria/jour/9.4.18]

(Author's translation).

Mutual help or aid was clearly seen in how the participants carried out the process of composing and typing scripts, preparing costumes and lending equipment such as laptop computers, finding the props, providing a scenario, correcting the style of acting partners as required fictional character, making-up and helping a friend in dressing. Participants preferred the interest of the group (team-work) to achieve planned goals in the classroom.

Refer to the following interview:

Participant3: "More fun to learn moral in this way... we now ... more than happy with moral are activities that involve all of us, it's more interesting and fun ... Other than that, now we are on good terms with all our classmates.. we respect each other ... we also respect the self-esteem of our friends ...we will not fight and hurt our friends feeling" [SMKSinar/inter/28.2.18] (Author's translation).

\subsection{Skills in resolving conflicts rationally}

According to observers, practices such as trying hard and not easily giving up hope are, shown by participants. Participants said they were willing to act together with their friends even though many could not easily lead the character given to them. While many still relied on the scripts written down (rather than memorizing the script) they still acted with confidence and kept acting in the anti-model play to the end. Their attitude and their confidence levels were also good and they were not even bothered with cheers and shouts of the spectator. Participants were confident in the ability of themselves. [Surya/Obr/yoka/26.2.18]

Meantime, observations also show that the group has been criticized by the actors (spect-actors) for not enact anti-model play very well. However, according to observers participants can show a good performance and to convince the audience in the intervention play. Participants have a strong self- 
endurance to continue a difficult task. [Sinar $/$ Inter/Ros/5.3.18]

Analysis of observation findings are supported by interviews with participants. Participants believe an attitude of trust motivated them to act or do a job or an assignment.

Participant 2: After teacher demonstrated to us how to be in the theatre and the way the play must perform, we bit confident. We believe and can act well. We realize if we do not believe in making this, we must not be made ... today we all believe in acting.

[Sinar/Inter/009/28. 2.18]

Participant 4: Forum Theatre makes us more rational and give us problem-solving skills. Various events such as writing the script and acting actually increase our self-confidence to do the work. We believe in acting and we act in front of the class. We realize everyone else can act in front of the class.

[Suria /Inter/010/12. 3.18]

The journal entries indicate the success of their roles and their first attempt has reinforced the confidence of participants. They did not give up hope. Failure to do the first turn was regarded as the driving force to continue to work harder to solve a given problem. Furthermore, participants' journal entries also confirmed their competent practice. They acknowledged that the positive praise also create confidence in the abilities of the participants themselves. They could carry out their assignment without any fear.

After our success of group was praised by friends and teacher Nada, I believe in acting of intervention play once again. I'm more

confident when teacher Nada supported us with playing a brother character in our play. [Sinar/Jur/ R3/ 6.3.18]

I can do the best with the confidence because there is a motivation from teacher Nada. I have tried to act with courage and confidence. [Suria/Jur/R4/ 9.4.18]

I'm satisfied with my casting in intervention play. Before the play I'm confident that I can do well and I believe that I can do, to make sure our success. [Cahaya/Jur/R5/ 4/11/18]

Analysis of the source of findings showed that all participants believed in their own ability. In addition, moral support from friends and teachers also encouraged good practice. Self-confidence in the ability to solve problems was also obvious amongst them.

\section{CONCLUSION}

In this article, the authors provided readers with some framework for the principles and practices of
Forum Theatre in a Moral Education classroom setting. Forum Theatre greatly enhanced students' classroom experience in learning. In particular, its value in creating an environment conducive to learning, experiential learning, moral reasoning, creativity, empathy, leadership, co-learning and moral behavior enhanced the amount of exchange and exploration that took place. Indeed, the researchers have no doubt that engaging with Forum Theatre as a classroom tool has a very positive impact for Moral Education students.

\section{REFERENCES}

1. Alam Sher Malik. (2012, May 27). Teaching is a performing art: Enliven the lesson at all its stages. New Sunday Times, p. 25.

2. Babbage, F. (2004). Augusto Boal. New York, NY: Routledge.

3. Boal, A. (2006). The aesthetics of the oppressed. Oxford: Routledge.

4. Boal, A. (2008). Theatre of the oppressed (new edition). London, UK: Pluto Press.

5. Boeije, H. (2010). Analysis in qualitative research. Thousand Oaks, CA: Sage.

6. Bogdan, R. C., \& Biklen, S. K. (2007). Qualitative research for education: An introduction to theories and methods. New York, NY: Pearson.

7. Boggs, J. G., Mickel, A. E., \& Holtom, B. C. (2007). Experiential learning through interactive drama: An alternative to student role-plays. Journal of Management Education, 31(6), 832-858.

8. Braun, V., \& Clarke, V. (2006). Using thematic analysis in psychology. Qualitative Research psychology, 3(2), 77-101.

9. Chang, L. H. (June, 2007). Moral reasoning of Malaysian adolescents. Paper presented at the International Conference on Learning, Johannesburg, South Africa.

10. Chickering, A., \& Gamson, Z. (1987). Seven principles for good practice in undergraduate education. Wingspread Journal. Winona, MN: Winona State University.

11. Cohen, J., \& Geier, V. (2010). School climate research summary. School Climate Brief, 1. New York, NY: National School Climate Centre. Retrieved from www.schoolclimate.org/climate/research.php

12. Creswell, J. W. (2012). Educational research: Planning, conducting, and evaluation quantitative and qualitative research (4th ed.). Englewood Cliffs, NJ: Pearson.

13. Dale, E. (1969). Audio-Visual methods in teaching (3rd ed.). New York, NY: Holt, Rinehart \& Winston.

14. Day, L. (2002). Putting yourself in other people's shoes: The use of forum theatre to explore refugee and homeless issues in schools. Journal of Moral Education, 31(1), 21-34.

15. Gourd, K. M., \& Gourd, T. Y. (2011). Enacting democracy: Using Forum Theatre to confront 
bullying. Equity \& Excellence in Education, 44(3), 403-419.

16. Hess, D. E. (2009). Controversy in the classroom: The democratic power of discussion. New York, NY: Routledge.

17. Ibrahim Bajunid. (2012, June 22). Education reforms that are ideal: Matters that need attention: Consensus building crucial to charting our future. New Straits Times, p. 18.

18. Kincheloe, J. (2008). Knowledge and critical pedagogy: An introduction. Amsterdam, The Netherlands: Springer.

19. Liau, A. K., Liau, A. W. L., Teoh, G. B. S., \& Liau, M. T. L. (2003). The case for emotional literacy: The influence of emotional intelligence on problem behaviours in Malaysian secondary school students. Journal of Moral Education, 32(1), 51-66.

20. Lickona, T. (1996). Eleven principles of effective character education. Journal of Education, 25(1), 93-100.

21. Lim, C. H. (2007). Penyelidikan pendidikan: Pendekatan kuantitatif dan kualitatif. Shah Alam: McGraw-Hill.

22. Malaysia Ministry of Education (MOE). (2000). Moral Education Syllabus for secondary school Malaysia. Kuala Lumpur: Curriculum Development Centre.

23. Marohaini Yusoff. (2001). Penyelidikan kualitatif: Pengalaman kerja lapangan kajian. Kuala Lumpur: Penerbit Universiti Malaya.

24. McClimens, A., \& Scott, R. (2007).Lights, camera, education! The potentials of forum theatre in alearning disability nursing program. Nurse Education Today, 27(3), 203-209.

25. Merriam, S. B. (2009). Qualitative research: A guide to design and implementation. San Francisco: Jossey-Bass.

26. Nadarajan Thambu, \& Muhammad Hasbi Abdul Rahman. (2017). Forum Theatre as a behavior change strategy: Qualitative findings from Moral Education class. SEARCH: The Journal of The South East Asia Research Centre for Communications and Humanities, 9(1), 25-46.

27. Narvaez, D., \&. Lapsley, D. K. (eds). (2008). Moral Personality, Identity, and Character: An Interdisciplinary Future. Cambridge, UK: Cambridge University Press.

28. Osburn, K. M. (2010). Forum Theatre Empowering Students to speak, Act and Know. Unpublished Bachelor's Dissertations, Western Kentucky University. Retrieved from http://digitalcommons.wku.edu/stu_hon_theses/245

29. Piantanida, M., \& Garman, N. B. (1999). A qualitative dissertation: A guide for students and faculty. Thousand Oaks: Sage.

30. Rae, J. (2013). Facilitating learning spaces in forum theatre. European Journal of Training and Development, 37(2), 220-236.
31. Richards, L., \& Morse, J. M. (2007). Readme first for a user's guide to qualitative methods. London: Sage.

32. Robinson, V. M., \& Lai, M. K. (2006). Practitioner research for educators: A guide to improving classroom and schools. Thousand Oaks, CA: Corwin Press.

33. Spring, J. (2006). Pedagogies of globalization: The rise of the educational security state. Mahwah, New Jersey: Lawrence Erlbaum Associates, Publishers.

34. Thambu, N., Naidu, N. B. M., \& Othman, M. A. (2018). Pemerkasaan pedagogi kritis untuk menjana Kemahiran Berfikir Aras Tinggi (KBAT) melalui teknik Teater Forum dalam kalangan murid Pendidikan Moral di sekolah menengah. Unpublished monograf, Universiti Pendidikan Sultan Idris, Perak.

35. Thambu, N., \& Shanmugavelu, G. (2016). Element of Moral Intent in Theatre Forum: An Action Research in a Moral Education Class. Asian Education Action Research Journal (AEARJ), 5, 114.

36. Torrance, E. P. (1983). Creativity in the classroom. Washington, DC: Library of Congress.

37. Vishalache Balakrishnan. (2011). Real-life dilemmas in moral education. Kuala Lumpur: University of Malaya Press.

38. Vishalache, B., \& Claiborne, L.B. (2012). Vygotsky from ZPD to ZCD in moral education:reshaping Western theory and practices in local context. Journal of Moral Education, 41(2), 225-243. 